\title{
Quantum of Space of the Universe-Correction of Previous Mistakes
}

\author{
Valentyn Nastasenko \\ Kherson State Maritime Academy, Kherson, Ukraine \\ Email: nastasenko2004@ukr.net
}

How to cite this paper: Nastasenko, V. (2021) Quantum of Space of the Universe-Correction of Previous Mistakes. Journal of Applied Mathematics and Physics, 9, 565-576.

https://doi.org/10.4236/jamp.2021.94040

Received: February 16, 2021

Accepted: April 12, 2021

Published: April 15, 2021

Copyright ( $) 2021$ by author(s) and Scientific Research Publishing Inc. This work is licensed under the Creative Commons Attribution International License (CC BY 4.0).

http://creativecommons.org/licenses/by/4.0/

\begin{abstract}
A large number of scientific works, from ancient times to the present, have been dedicated to the search for "bricks" that make up the foundations of the material world. Justification of quantum of space parameters of the Universe is a complicated scientific problem, as its reliable information is unknown. Therefore, errors may appear in it, which must be corrected in a timely manner. In the latest works from this sphere, the quanta of the space of the Universe are replaced by hexahedral prisms instead of balls, which solves the problem of their dense packing. However, the mistake was the deformation of these prisms. The purpose of this work is to eliminate this deficiency. Its scientific novelty is the substantiation of the specified of refined parameters of the quantum of the space of the Universe on the basis of strict scientific provisions and the physical laws of nature. The solution to this problem is an urgent and important scientific and applied task, since it develops knowledge about the quantum foundations of the material world and the Universe as a whole. Research methods which used in this work: The performed work is based on the methods of deduction and induction in the research of the material world based on the application of the well-known reliable laws of physics and the general principles of the development of the theory of knowledge. Other research methods are still unknown, since the work performed is associated with new scientific discoveries, the search for which is difficult to formalize by known technique methods. Results and their discussion: The work is based on the hypothesis that was put forward that at the quantum-mechanical level of the material world, a longitudinal quantum shift by the wavelength $\lambda_{G}$ and a transverse quantum shift by $\lambda_{G}$ of the quantum of the Universe space is carried out in the time interval $T_{G}$ which can be found on the basis of the Heisenberg uncertainty principle. The parameters obtained made it possible to clarify the length and shape of quanta of the space of the Universe, as well as the conditions for its rotation. It was also taken into account that the hexagonal prism of the circular quantum of the space of the Universe is composed of 6 trihedral prisms of elementary quanta of space. So
\end{abstract}


she can be formed by 3 elements of real quark with a common top in the center of the prism, with the formation of 3 elements of virtual quark between them. In this case, a transverse shift by $\lambda_{G}$ and a rotation of quarks by an angle of $2 \pi / 6$ radians is performed without energy loss, only due to transformations of their real and virtual states. The totality of all the above transformations of quanta of the space of the Universe does not contradict previously known physical laws and regularities, which serves as the basis for confirming the scientific hypothesis put forward.

\section{Keywords}

Quantum of Space of the Universe, Subject to Its Formation and Functioning

\section{Introduction}

There is a "catch phrase"- the one who does nothing is not mistaken. It is important to see mistakes and correct them in time. There are especially many mistakes in quantum physics, where many of the starting positions are based on axioms and postulates.

One of such extreme spheres of the unknown is the problem of determining the quantum of the space of the Universe. A large number of scientific works, from ancient times to the present, have been dedicated to the search for "bricks" that make up the foundations of the material world. Currently, the most complete in this area are works [1] [2] [3] [4] in which the shape and parameters of the quantum of space were determined on the basis of strict scientific provisions and physical laws. Before that, there were only hypothetical works, for example in [5], which the shape of the quantum of space was not determined and it boiled down to abstract reasoning without specific values of the sought parameters. Approximate numerical parameters are proposed only for time quanta, as a value of $10^{-33} \mathrm{~s}[6]$.

In [1] on the base framework of general principles solution of scientific-technical problems [7], two original subproblems were of the outlined and resolved: $A$-definition of form the quantum of space; $B$-definition of parameters the quantum of space.

Traditional concept about of form quanta of space in the shape of balls, that has a minimum diameter $D_{\text {min }}$, is unacceptable, as they should be tightly packed, and balls leave empty space in between. A small ball with diameter $d$, which is lesser than diameter $D_{\min }$ can be inscribed into this space. This condition contradicts the principle of quantum minimalist reaching. In a piece of work performed earlier [8] which is little known, provision has been made to the conclusion that the tight packing of not compressible and indivisible quantum particles is contributed by the elementary scheme, shown in (Figure 1). This structure makes in the shape of regular trihedral prisms of elementary quanta of space, and 6 of them-make up the circular quantum of the space of the Universe. 


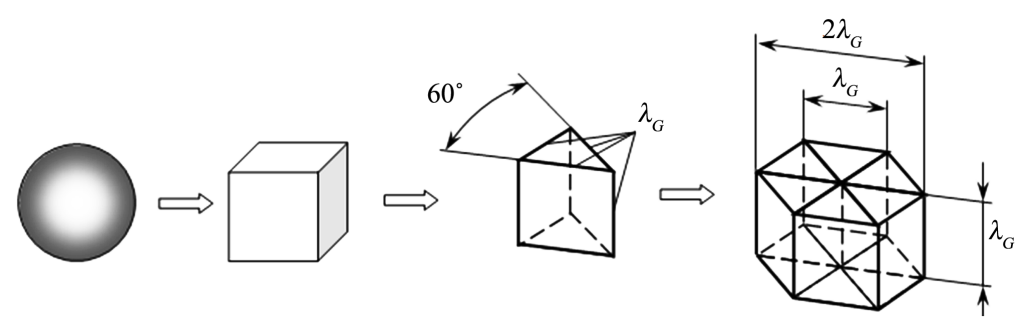

Figure 1. The quantum of space in the universe, general idea [1].

Parameters $\lambda_{G}$ are also difficult to be defined as the quantum of space should be the minimal possible value in the Universe, and its limits. These limits and the possibility of these limits existence themselves have not been well grounded. It is explained by suggested by philosophers a hypothesis in the 20th century [9] about the infinite reduction opportunities of material world objects in the frameworks of inexhaustibility of structure electron [1]. The length $\lambda_{G}$ is related to the wavelength of the gravitational field, the magnitude of which was determined in [10] [11] [12]. The connection of the quantum parameters found with the gravitational field gives them a rigorous physical meaning and makes the solution of the problem of their numerical determination rigorous, since dependencies [10] [11] [12] are based on 3rd fundamental physical constants [13]:

- Speed of light in vacuum $c$.

$$
c=0.299792458 \times 10^{9}(\mathrm{~m} / \mathrm{s}),
$$

- Plank's constant $h$ :

$$
h=6.626070040 \times 10^{-34}(\mathrm{~J} \cdot \mathrm{s})=6.626070040 \times 10^{-34}\left(\mathrm{~kg} \cdot \mathrm{m}^{2} / \mathrm{s}\right),
$$

- Gravitational constant $G$ :

$$
G=6.67408(31) \times 10^{-11}\left(\mathrm{~m}^{3} / \mathrm{kg} \cdot \mathrm{s}^{2}\right) .
$$

1) Strict definition of the gravitational field waves frequency $v_{G} \rightarrow 7.4 \times 10^{42}$ $\mathrm{Hz}$ (its constant Nastasenko).

$$
\begin{aligned}
v_{G} & =\sqrt{\frac{c^{5}}{G h}}=\sqrt{\frac{\left[0.299792458 \times 10^{9}(\mathrm{~m} / \mathrm{s})\right]^{5}}{6.67408 \times 10^{-11}\left(\mathrm{~m}^{3} / \mathrm{kg} \cdot \mathrm{s}^{2}\right) \cdot 6.626070040 \times 10^{-34}\left(\mathrm{~kg} \cdot \mathrm{m}^{2} / \mathrm{s}\right)}} \\
& =7.39994 \times 10^{42}\left(\mathrm{~s}^{-1}\right) .
\end{aligned}
$$

Since the constant $v_{G}$ is obtained on the basis of the fundamental physical constants $c, G, h$ by of strict physical dependence (4), the negation of $v_{G}$ is equivalent to the negation of the constants $c, G, h$. On their basis, M. Planck determined the time metric in seconds [14], which is recognized an abstract quantity, and the frequency $v_{G}$ is the real quantity, which is the opposite of the time metric. To find, it's necessary to change the vector of thinking, which M. Planck did not do and among the parameters he found there is no value $7.4 \times 10^{42} \mathrm{~Hz}$. Since this constant was not previously known and was obtained on the basis of strict physical law (4), therefore she has a level of scientific discovery [15], to which the author has the right to give his name [15]. 
2) On the grounds of the found frequency (1) and known earlier wave laws [14], a wavelength of gravitational field $\lambda_{G}$ can be defined (2):

$$
\lambda_{G}=\frac{c}{v_{G}}=\frac{0.299792458 \times 10^{9}(\mathrm{~m} / \mathrm{s})}{7.4 \times 10^{42}\left(\mathrm{~s}^{-1}\right)}=4.051249|432| \times 10^{-35}(\mathrm{~m}) .
$$

It should be taken into account that not a single modern quantum theory, which is built on tensor equations and other types of abstract mathematical dependencies, allows one to determine either the specific form or the real parameters of quanta of the space of the Universe, and especially-his numerical parameters.

In [2] it is shown that the prismatic shape of the quanta of space also does not meet the criteria of minimalism. Therefore, in [2] it is proposed to replace the square at the end of the prism with a regular triangle, which reduces the quantum of the Universe space to a complex figure, which is shown in Figure 2.

The conditions of rotation between themselves and rotation of space quanta are also considered [2].

It was shown in [3] that there is no stable limiting separating planes in elementary and circular quanta of space, since dislocation along them is impossible, and the edges, along which motion is possible within the framework of the Heisenberg uncertainty principle [14]. He has blurry configurations (spots) interpenetrating together (Figure 3) [3].
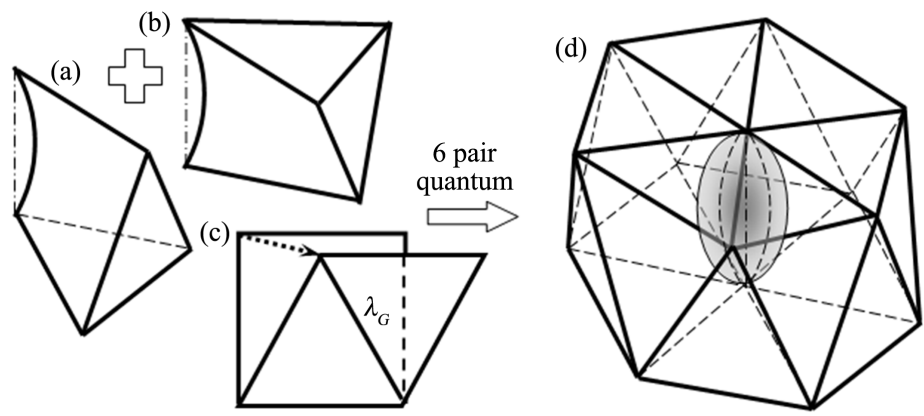

Figure 2. New image of a quantum of space of the Universe and scheme of its formation: (a) elementary quantum; (b) antipode; (c) deformation of a lateral square of elementary quantum in a rhombus; (d) new circular quantum [2].

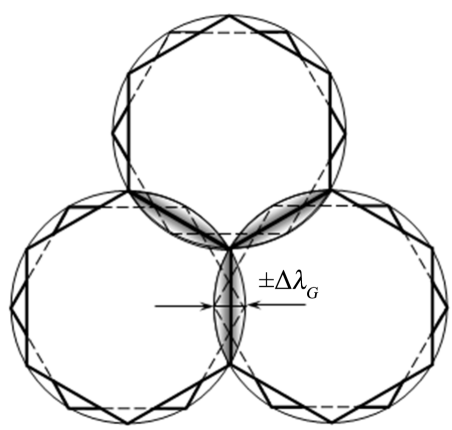

Figure 3. Packing of the quantum's space of the rotated with each other in the zones of their mutual penetration [3]. 
The form and parameters of the quanta of the space of the Universe and photon (Figure 4) are substantiated on the basis of revealing the connection between the quantum of the space and its other objects of the quantum level. In this case, the quantum of the space is motionless, and photon makes a translational motion with rotation [3].

In this case, a complete rotation $2 \pi(\mathrm{rad})$ is carried out in 12 clock cycles of the linear motion of the photon.

Also in [3], hard edges of the quanta of space were replaced by fuzzy connections with the concentration of these structures in the nodes at the vertices (Figure 5).

In [4], the problem of quantizing not only space, but also time, which were strictly related to the wave and energy parameters of the gravitational field [10] [11] [12], is considered.

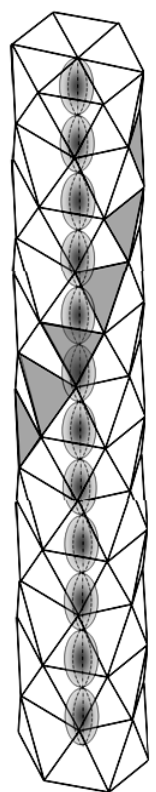

(a)

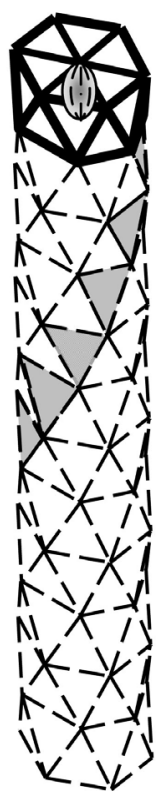

(b)

Figure 4. The form and parameters of the motionless quantum's of the space of the Universe (a) and translational motion with rotation photon (b) [3].

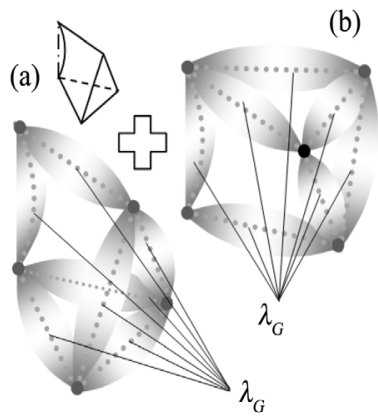

(b)<smiles>C1C2CC1C2</smiles>

(c)

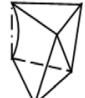

(d)

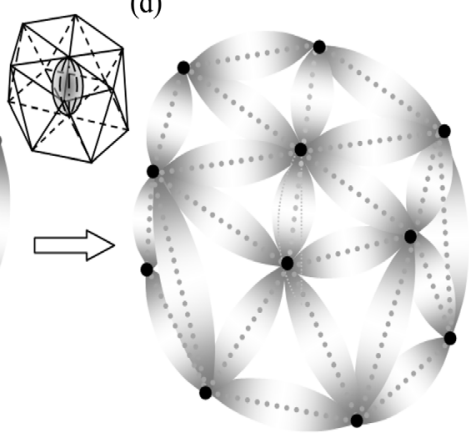

Figure 5. Formation of ribs of elementary quantum (a), antipode (b), paired quantum dipole (c) and circular quantum (d) by fuzzy connections. 
Each of these works contributed to the solution of the problem of quantization the space of the Universe; therefore, without completing the previous work, the next step would be impossible. The completeness of the solution to the problem increased from work to work and reached its maximum in [4].

However, works [2] and [3] cannot be considered final, since its further analysis made it possible to single out its main contradiction: the speed of the forward motion of the photon became less than the speed of light $c$. Correcting this error is the main goal of the work being done. Its scientific novelty is the substantiation of the specified of refined parameters of the quantum of the space of the Universe on the basis of strict scientific provisions and the physical laws of nature.

The solution to this problem is an urgent and important scientific and applied task, since it develops knowledge about the quantum foundations of the material world and the Universe as a whole.

\section{Working Methods}

The performed work is based on the methods of deduction and induction in the research of the material world based on the application of the well-known reliable laws of physics and the general principles of the development of the theory of knowledge that follows from it and are rigorously confirmed by previously known reliable laws of physics. Other of theoretical research methods are still unknown, since the work performed is associated with new scientific discoveries, the search for which is difficult to formalize by traditional methods of conducting scientific research.

\section{Results and Their Discussion}

To solve the problem posed in this work, the starting points are:

1) General principles of structuring the levels of the material world [16];

2) The consistency of the process of searching for new scientific solutions on base to the already known laws of nature [17];

3) The consistency of the development of scientific knowledge from simple constituent elements to more complex system [16];

4) The principle of minimalistic of changes in phenomena and actions at the quantum level, which is confirmed by the Pauli principle [14].

Analysis of the longitudinal and transverse structure of quanta of the space of the Universe based on the principles of work [2] showed that they were performed with axial compression of a quantum (Figure 2) and a blurred shape of its edges with mutual penetration of edges (Figure 3 ). However, the general principles of construction and their similarity with a photon, which is shown in Figure 4(a) and Figure 4(b), allows us to conclude that the total speed of translational motion of photons (Figure 4(b)) decreases compared to the initial speed of light $c$, which contradicts their real movement. Therefore, the general principles of construction and the similarity of the systems shown in Figure 4(a) and 
Figure 4(b) allow us to conclude that the parameters of the quantum of the space of the Universe should not have the compression shown in Figure 2.

The representation of a quantum of space by nodes (Figure 5) is also erroneous, since it does not correspond to the general principles of quantization (Figure $1)$.

Thus, in [2] and [3], when developing the schemes shown in Figures 2-5, there was inertia of thinking and the transfer of characteristics of the level of interaction of elementary particles and atoms to the quantum-mechanical level of material world.

To correct this drawback, a hypothesis was put forward that at the quantum-mechanical level of the material world, a longitudinal quantum shift by the wavelength $\lambda_{G}$ and a transverse quantum shift by $\lambda_{G}$ of the quantum of the Universe space is carried out in the time interval $T_{G}$ :

$$
T_{G}=1 / v_{G}=0 .|135| \times 10^{-42}(\mathrm{~s})
$$

where $v_{G}$-the oscillation frequency of the gravitational field waves (3).

The value of $T_{G}$ can be found on the basis of the Heisenberg uncertainty principle from dependence (9) [14]:

$$
\Delta x \Delta v>h / m,
$$

where $\Delta x$-the uncertainty of the spatial coordinate of the microparticle;

$\Delta v$-the uncertainty of the velocity of the microparticle;

$m$-the mass of a microparticle;

$h$-Planck's constant (2).

In this case, the six-sided base of the quantum of space is associated with the event horizon, and over the time period $T_{G}$ the longitudinal shift of this base transfers it to a new event horizon with a transverse turn by $2 \pi / 6$ radian for each step of longitudinal shift. In the interval of this time $T_{G}$, the quantum of the space of the Universe has an indefinite (unmanifest) state. In this case, the spherical quantum layer becomes a single layer in which you can stay everywhere and nowhere, and its energy is uniform and can manifest itself in full at any place in the sphere.

It should be noted that quantum physics is mainly based on hypotheses, axioms and postulates, therefore, the hypothesis of the jump and rotation of the quantum of space during the Heisenberg uncertainty period is admissible and it is required to justify it.

Since the spherical layer of these quanta is formed by a spherical wave of the gravitational field with a radial wavelength in the layer $\lambda_{G}=c / v_{G}$ therefore, in the framework of the equality of Plank's energy law $E_{G}=h v_{G}$ and Einstein's law $E_{G}=m_{G}{ }^{2}$, its energy mass $m_{G}$ can be determined from the dependence (8):

$$
\begin{aligned}
m_{G} & =\frac{E_{G}}{c^{2}}=\frac{h v_{G}}{c^{2}}=\frac{6.626070040 \times 10^{-34}\left(\mathrm{~kg} \cdot \mathrm{m}^{2} / \mathrm{s}\right) \times 7.4 \times 10^{42}\left(\mathrm{~s}^{-1}\right)}{\left[0.299792458 \times 10^{9}(\mathrm{~m} / \mathrm{s})\right]^{2}} \\
& =5.455647929 \times 10^{-8}(\mathrm{~kg}) .
\end{aligned}
$$


Transforming dependence (7) taking into account dependence (8), we obtain a new expression for the Heisenberg uncertainty law (9):

$$
\Delta x \Delta v>c^{2} / v_{G}
$$

Taking into account that within the framework of the unity of the gravitational and electromagnetic fields, proved in [18] [19] [20], the speed $v$ of motion of the waves of the gravitational field will be the value $\Delta v=\mathrm{c}$, therefore the uncertainty (9) is transformed into (10):

$$
\Delta x=\frac{c}{v_{G}}=\frac{0.299792458 \times 10^{9}(\mathrm{~m} / \mathrm{s})}{7.4 \times 10^{42}\left(\mathrm{~s}^{-1}\right)}=4.051249|432| \times 10^{-35}(\mathrm{~m}) .
$$

The quantity (10) is the exact value of the length of the quanta of space (5), which on a strict basis confirms the ratio of the event horizons for its upper and lower sides. Therefore, in the original Figure 2 and Figure 4, the central clots should be excluded, and the height of the quanta of the space of the Universe should be increased to the value (5). In this case, there are no angular movements: there are only 2 simultaneous steps forward and movements to the side. The number of steps before the full rotation of the quantum of space decreases from 12 to 6, so their new appearance is shown in Figure 6.

In further analysis, it was taken into account that the hexagonal prism of the circular quantum of the space of the Universe is composed of 6 trihedral prisms of elementary quanta of space. It was also taken into account that their three-sided shape can be associated with quarks. Therefore, a hexahedral prism of a circular quantum of space can be formed by 3 composition elements of real quark with a common top in the center of the prism, with the formation of 3 composition elements of virtual quark between them (Figure 7).

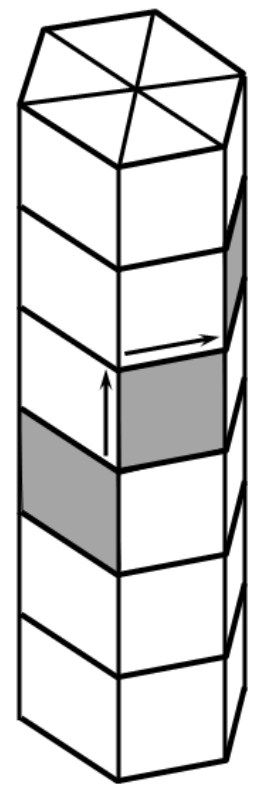

Figure 6. Refined form of quanta of the space of the Universe and the scheme of their rotation. 


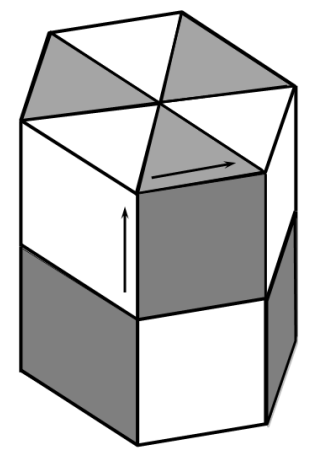

Figure 7. Connection of quarks with a quantum of space of the Universe, a quark is highlighted in gray, a virtual quark is highlighted in white.

Only this form of a quark is associated with the proposed principles of quantizing the parameters of the Universe, which can serve as an indirect proof of the correctness of the scientific hypothesis put forward in this work. The connection with the quark, which consists of 3 constituent elements, makes it possible to assert that the quantum of the space of the Universe is not a trihedral prism, but a hexahedral prism, which consists of 6 of these trihedral prisms.

In this case, a transverse shift by $\lambda_{G}$ and a rotation of quark by an angle of $2 \pi / 6$ radians is performed without energy loss, only due to transformations of his real and virtual states. The process of such transformations is endless and inexhaustible, since it occurs with symmetric absorption and release of the energies of direct and inverse transformations of real and virtual quarks. Thus, the state of the initial event horizon during the period of uncertainty $T_{G}$ passes into the state of a new horizon by a quantum leap in its final form without energy loss. Justification of the possibility of a transverse rotation of a quantum of space by successive replacement one after another of real and virtual quarks was proposed for the first time. It is also shown for the first time that quarks form and maintain the internal state of quanta of the space of the Universe. This corresponds to the level of scientific discoveries [15].

Taking into account the connection of quanta of the space of the Universe with the parameters of the gravitational field, it can be assumed that this quantum is actually a graviton, and the space of the Universe is structured by gravitons.

The totality of all the above transformations of quanta of the space of the Universe does not contradict previously known physical laws and regularities. All transformations develop logically on the basis of the dialectic of scientific knowledge when moving from simple constituent elements to their more complex forms. At the same time, the principle of minimality of changes in phenomena and actions at all levels is observed, which serves as the basis for confirming the scientific hypothesis put forward.

\section{Conclusions and Recommendations}

1) The erroneous representation of the elementary and circular prismatic 
quanta of the space of the Universe with the deformation of their middle zone is shown.

2) On the basis of consistent initial scientific provisions and general principles of their further development, a new form of the quantum of the space of the Universe and the process of its formation is substantiated.

3) It is shown that the formation of a quantum of the space of the Universe is carried out at each subsequent event horizon by longitudinal quantum jumps by the value of the wavelength of the gravitational field and transverse jumps by the same length with a rotation by an angle of $2 \pi / 6$ at each jump when passing through the Heisenberg uncertainty phase.

4) A model of the formation of the rotation of space quanta at an angle of $2 \pi / 6$ on the basis of the mutual transition of pairs of real and virtual quarks is proposed, which excludes energy consumption which can be used as the basis for representing of real processes of material world.

5) Quarks form and maintain the internal state of quanta of the space of the Universe.

\section{Conflicts of Interest}

The author declares no conflicts of interest regarding the publication of this paper.

\section{References}

[1] Nastasenko, V.A. (2019) Definition Form and Parameters of Quantum of Space of the Universe. International Journal of Astronomy and Astrophysics, 1, 42-45. https://doi.org/10.18689/ijcaa-1000111

[2] Nastasenko, V.A. (2019) Refinement the Form and Parameters of Quantum of Space of the Universe. Journal Cosmological Astronomical Astrophysics, 1, 62-66. https://doi.org/10.18689/ijcaa-1000115

[3] Nastasenko, V.A. (2019) New Quantum of the Space of the Universe and New Opportunities for the Development of Quantum Physics. Journal Cosmological Astronomical Astrophysics, 1, 71-76. https://doi.org/10.18689/ijcaa-1000117

[4] Nastasenko, V. (2021) Problems of Quantizing the Material World and Possibilities of Its Solution. 2nd International Scientific and Practical Conference, Luxembourg, 26-28 January 2021, 443-448. https://isg-konf.com

[5] Skorost' sveta i kvantovaniye vremeni. (2009) Speed of Light and Time Quantization. http://www.chronos.msu.ru/old/discussions/kabulov_skorost.html

[6] Wendel, G., Martínez, Luis and Bojowald, M. (2020) Physical Implications of a Fundamental Period of Time. Physical Review Letters, 124, Article ID: 241301. https://doi.org/10.1103/PhysRevLett.124.241301

[7] Nastasenko, V.A. (2016) Metodologiya resheniya tvorcheskikh zadach vysokogo urovnya slozhnosti i vozmozhnosti yeye svyazi s sistemami iskusstvennogo intellekta [Methodology for Solving Creative Problems of a High Level of Complexity and the Possibility of Its Connection with Artificial Intelligence]. Institut Iskusstvennogo Intellekta, 4, 53-59. (In Russian)

[8] Nastasenko, V.A. (2012) Obosnovaniye parametrov minimal'nogo kvanta prostranstva Vselennoy [Ground of Parameters Minimum Quantum of Space of Un- 
iverse]. Scientific Bulletin KhDMA, 1, 285-297. (In Russian)

[9] Lenin V.I. (1976) Materialism and Empiriocriticism [Materialism and Empiriocriticism]. Political Literature Publishing House, Moscow, 277. (In Russian)

[10] Nastasenko, V.A. (2013) O vozmozhnosti utochneniya znacheniya gravitacionnoyj postoyannoyj raschetnihm putem [On the Possibility of Clarifying the Value of the Gravitational Constant by calculation]. Megdunarodnaja nauchno-technisheskaja konferencia Vihsokoproizvoditeljnihe vihchisliteljnihe sistemi, National Technical University of Ukraine "Igor Sikorsky Kyiv Polytechnic Institute", Kyiv, 266-272. (In Russian).

[11] Nastasenko, V.A. (2014) O vozmozhnosty opredelenyya volnovykh parametrov hravytatsyonnoho polya [On the Possibility of Determining the Wave parameters of a Gravitational Field]. Visnyk Khersons'koho natsional'noho Tekhnichnoho Universytetu-Kherson. Kherson National Technical University, Vyp, 1, 71-76. (In Russian)

[12] Nastasenko, V.A. (2018) Discovery of Analytical Method Defined of Wave Parameters Gravitation Field. Valentyn Alekseevitcn Nastasenko Journal Laser Opt Photonicsm, 5, 1 .

https://www.omicsonline.org/conference-proceedings/physicists-congress-2018-scie $\underline{\text { ntifictracks-abstracts.digital/files/assets/basic-html/page-12.html }}$

[13] Committee on Data for Science and Technology (2018) Internationally Recommended Values of the Fundamental Physical Constants. https://physics.nist.gov/cuu/Constants/index.html

[14] Alekseev, D.V., Bonch-Bruevich, A.M., Voronov-Romanov, A.S., et al. (1983) Phizicheskij encyclopedicheskij slovar [Physical Encyclopaedic Dictionary]. In: Prohorov, A.M., Ed., Pod Red, Sov. Encyclopedia, Moskow, 86, 256, 523, 544. (In Russian).

[15] Civiljniyj kodeks Ukrainu [Civil Code of Ukraine] (2003) Zakonu Ukrainu. Shkola, Kyiv. (In Ukrainian)

[16] Nastasenko, V.A. (2020) Novyy uroven' differentsiatsii material'nogo mira i yego obosnovaniye [A New Level of Differentiation of the Material World and Its Substantiation]. IV Mezhdunarodnaya nauchno-prakticheskaya konferentsiya Science, Society, Education: Topical Issues and Development Prospects, 17-18 marta $2020 \mathrm{~g}$. Khar'kov, Ukraina. 202-206.

https://sci-conf.com.ua/iv-mezhdunarodnaya-nauchno-prakticheskaya-konferentsi ya-science-society-education-topical-issues-and-development-prospects-16-17-mar ta-2020-goda-harkov-ukraina-arhiv [In Russian]

[17] Peshcherov, G. (2017) Metodologiya nauchnogo issledovaniya: ucheb. posobiye/ Georgiy Peshcherov, Oleg Slobotchikov. [Methodology of Scientific Research: Textbook. Allowance]. Institut mirovykh tsivilizatsiy, Moscow.

[18] Nastasenko, V.A. (2014) Novye osnovy dlya strohoho opredelenyya volnovykh parametrov hravytatsyonnoho polya y ob"edynenye hravytatsyonnoho y élektromahnytnoho poley [New Bases for Strict Determination of the Wave Parameters of the Gravitational Field and the Union of Gravitational and Electromagnetic Fields]. Naukovyy visnyk KHDMA: Naukovyy Zhurnal.-Kherson, KHDMA, vol. 1, 213-222. http://www.irbis-nbuv.gov.ua/cgi-bin/irbis_nbuv/cgiirbis_64.exe?I21DBN=LINK\&

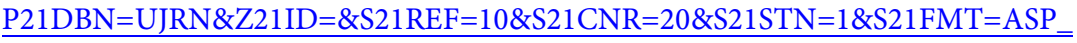
meta\&C21COM=S\&2_S21P03=FILA=\&2_S21STR=Nvkhdmi_2014_1_31 [In Russian]

[19] Nastasenko, V.A. (2018) Possibility of Refining the Gravitational Constant and Solving the Task of Integrating the Gravitational and Electromagnetic Fields. Jour- 
nal of Astrophysics \& Aerospace Technology, 6, Article No. 155.

https://doi.org/10.4172/2329-6542.1000155

[20] Nastasenko, V.A. (2017) Union of Gravitational and Electromagnetic Fields on the Basis of Nontraditional Principles. Electrical \& Computer Engineering, 6, 19-30. https://doi.org/10.14810/ecij.2017.6402 